\title{
Un grand enterrement
}

Henri ROORDA

Écrivain

\begin{abstract}
Cette chronique de 1920 prolonge la réflexion pédagogique de Roorda en remettant en question l'utilité de certaines connaissances encyclopédiques transmises par l'école. À travers des exemples ciblés, le texte dénonce l'absurdité des éléments d'érudition retenus dans le domaine de l'histoire, en particulier sur son versant littéraire.

Keywords : Henri Roorda, pédagogie, postérité, histoire, histoire littéraire, René Duguay-Trouin, Chosoclès, Isaac de Benserade, Louis Bourdaloue, Montaigne, Pierre Corneille, Thomas Corneille.
\end{abstract}

Je voudrais qu'un jour Madame la Postérité me donnât des Pleins Pouvoirs pour juger en son nom deux ou cents personnages célèbres dont l'École entretient l'immortalité avec un zèle absurde et qui ne devraient occuper aucune place dans la mémoire des jeunes gens d'aujourd'hui. Le jour du jugement serait annoncé longtemps à l'avance ; et, aux assistants nombreux accourus pour entendre la sentence irrévocable, j'adresserais un discours dans le goût de celui-ci :

- «Mesdames, Messieurs, il est des morts qu'il faut qu'on tue.

Vous avez tous été à l'école ; et vos éducateurs vous ont longuement promenés dans le Cimetière de l'Histoire. Ils vous obligeaient à vous arrêter devant des tombes innombrables et, invariablement, ils vous disaient : « Retenez ce nom ; retenez cette date ! » Leur enseignement a été efficace, car toutes les écolières studieuses de votre ville savent que le corsaire Duguay-Trouin mourut en I736. Vous-mêmes, vous n'ignorez pas qu'il exista, au XVII e siècle, un monsieur qui s'appelait Anatole Benserade et qui composa des tragédies, des ballets et des madrigaux. Lorsqu'on nomme devant vous le célèbre Chosoclès, vous savez qu'il s'agit d'un général athénien qui se distingua dans la guerre du Péloponnèse. Et vous pouvez être fiers d'avoir été très souvent admis, pour une minute ou deux, dans la société des grands hommes.

Mais quels sont les plus jolis vers d'Anatole Benserade ? Quelles sont les phrases les plus éloquentes de Bourdaloue? L'École ne vous les a pas cités. Le Pédagogue apprécie moins le vin de la poésie que l'étiquette qui est sur la bouteille. Ce sont des étiquettes qu'il distribue principalement à ses élèves, en leur disant toujours avec sévérité : « Retenez ces noms, retenez ces dates. »

Eh bien moi, la Postérité, je commence à en avoir assez. Je suis littéralement sur les dents. L'humanité a beaucoup trop de demi-grands hommes. Il m'est impossible de m'occuper de tous ces vaniteux qui me crient : « Ne 
m'oubliez pas : je m'appelle Durand ». - «Ne m'oubliez pas, je m'appelle Dupont ». - « Ne m'oubliez pas, je m'appelle Sophie. » Nous allons les condamner à mort en cinq sec; et, désormais, nous ferons tous contre eux la conspiration du silence. Nous allons procéder à l'enterrement symbolique de ces morts récalcitrants. Mais ce second enterrement sera irrévocablement le dernier.

Les gens qui ont de bons yeux affirment que dans une goutte d'eau on retrouve l'univers. Je n'en suis pas bien sûr. Mais que ne trouve-t-on pas dans l'œuvre d'un Montaigne, par exemple? Nous ne conserverons dans notre Musée Humain que les vrais héros et les plus beaux spécimens de la faune littéraire. Ce sera plus que suffisant pour les êtres paresseux ou affairés que nous sommes.

Mesdames, Messieurs, nous possédons deux Corneille. Tenez-vous absolument à conserver Thomas ? Non. Thomas sera donc enterré sans phrases. Pendant plus d'un siècle, on nous a parlé d'un poète qui dit qu'au banquet de la vie il fut un infortuné convive. C'est sans doute très triste ; mais son cas n'est pas unique. Puisque ce malheureux n'a rien d'autre à nous raconter nous le ferons rentrer dans le néant. Voici Casimir qui nous prouve qu'il a écrit un livre. Mais cet exploit lui a déjà valu trois cents ans d'immortalité. C'est assez. Il est plus facile d'écrire un livre que d'être bon père et bon époux. Je prierai aussi Rotrou de bien vouloir rentrer dans le funèbre trou. Et que veut ce général ? Il prétend qu'il s'est bien battu. Il n'a fait que son devoir. Si les militaires n'avaient pas de courage, à quoi se réduiraient leurs vertus?

Sachez, Mesdames et Messieurs, que la liste complète des condamnés à mort sera publiée demain dans tous les journaux. J'ai encore à examiner quelques cas douteux.

Lorsque les gens économes enterrent un mort, ils lui enlèvent d'abord ses bagues et son dentier. J'aurai soin, également, de retenir dans une anthologie les trois ou quatre jolis vers et les quelques bons mots de chacun des écrivains que je condamnerai à l'oubli éternel. Mais je ne mettrai pas le nom d'un propriétaire sur ces choses qui sont tombées dans le domaine public.

Les maniaques de l'érudition (à condition d'avoir cinquante ans révolus) pourront visiter chaque jour le Cimetière des demi-grands hommes et s'y livrer à des fouilles discrètes. Mais les êtres jeunes ont autre chose à faire que de lire des noms sur des tombes. J'ai dit. »

Gazette de Lausanne, 5 février 1920 